\title{
Knowledge and Attitudes Regarding Exclusive Breastfeeding Among Mothers of 0-23 Months Children in Public Healthcare Centre in Togo
}

\author{
Compaore Wendinpuikondo Raketa Ella ${ }^{1,}$, , Agbokou Koffi Apéali Wassiou ${ }^{1}$, \\ Ouedraogo Ousmane ${ }^{1}$, Souho Tiatou ${ }^{2}$, Mouawiyatou Bouraima ${ }^{3}$, Virginio Pietra ${ }^{4}$, \\ Kiemde Wend-Lassida Michel Eric ${ }^{1}$, Zagre Marie Noel ${ }^{5}$, Amouzou Sabiba Kou'Santa Emile ${ }^{2}$, \\ Meda Nicolas ${ }^{6}$, Dicko Hama Mamoudou ${ }^{1}$ \\ ${ }^{1}$ Department of Biochemistry and Microbiology, University Joseph KI-ZERBO, Ouagadougou, Burkina Faso \\ ${ }^{2}$ Faculty of Sciences and Techniques, University of Kara, Kara, Togo \\ ${ }^{3}$ Division of Nutrition, Ministry of Health and Public Hygiene, Lome, Togo \\ ${ }^{4}$ Medicus Mundi Italy, Koudougou, Burkina Faso \\ ${ }^{5}$ United Nation Children's Fund, West and Central Africa Office, Dakar-Yoff, Senegal \\ ${ }^{6}$ Department of Public Health, University Joseph KI-ZERBO, Ouagadougou, Burkina Faso
}

\section{Email address:}

rakibf@gmail.com (C. W. R. Ella)

${ }^{*}$ Corresponding author

To cite this article:

Compaore Wendinpuikondo Raketa Ella, Agbokou Koffi Apéali Wassiou, Ouedraogo Ousmane, Souho Tiatou, Mouawiyatou Bouraima, Virginio Pietra, Kiemde Wend-Lassida Michel Eric, Zagre Marie Noel, Amouzou Sabiba Kou'Santa Emile, Meda Nicolas, Dicko Hama Mamoudou. Knowledge and Attitudes Regarding Exclusive Breastfeeding Among Mothers of 0-23 Months Children in Public Healthcare Centre in Togo. Central African Journal of Public Health. Vol. 6, No. 2, 2020, pp. 66-72. doi: 10.11648/j.cajph.20200602.13

Received: January 30, 2020; Accepted: February 11, 2020; Published: February 18, 2020

\begin{abstract}
The purpose of this study was to assess the knowledge and attitudes of mothers of children aged 0 to 23 months towards exclusive breastfeeding (EBF) in public health facilities in Lome, Togo. A cross-sectional, descriptive and analytical study was carried out over a period of two months among the target group who brought their children for consultation in the growth monitoring and promotion of health care Centre in Lome. The study involved 417 mostly primigravida and primiparous mothers averaging $28.4 \pm 0.3$ years old. Among these mothers $89.7 \%$ attended school and $99.2 \%$ had at least one antenatal visit. The most common sources of maternal awareness of infant and young child feeding (IYCF) were the services of expanded programme for immunization, EPI (62.6\%), antenatal care (58.5\%), and growth monitoring and promotion (53.7\%). The majority (82\%) of mothers agreed that EBF is feasible. However, only $43.9 \%$ and $19.7 \%$ of these mothers have a good knowledge of both benefits of EBF for the baby and the mother, respectively. Levels of mother's knowledge of the benefits of AME for mother and baby are dependent on sensitization by health workers $(P=$ $0.0001)$ and mass medium $(P=0.036)$.
\end{abstract}

Keywords: Exclusive Breastfeeding, Knowledge, Attitude, Togo

\section{Introduction}

In developing countries, breastfeeding remains an absolute imperative because of the safety it provides in the prevention of respiratory and digestive infections and its role in meeting the nutritional needs of the child $[1,2]$. Breastfeeding is exclusive when the infant receives only breast milk and no other liquid or solid food, not even water, with the exception of drops or syrups of vitamin and mineral supplements, or medications [3]. In 2016, despite strong and convincing arguments in favor of EBF, less than half of children under 6 months of age worldwide received breast milk as their only food. In Togo, despite the existence of recommendations on the promotion of the EBF, the demographic and health survey 
in 2014 revealed that in the greater Lome agglomeration (municipality of Lome and the urban areas of the Golfe prefecture), the median duration of exclusive breastfeeding was 2.9 months and the prevalence of EBF up to 6 months was $54.4 \%[4,5]$. These low rates could be the result of women not understanding information received during sensitization and socio-economic environments favoring inappropriate practices, including social norms, barriers related to health services and employment, and advertising of breast milk substitutes (BMS) [6-8]. The present study aims to assess the knowledge and attitude of mothers of children aged 0 to 23 months on exclusive breastfeeding in public health facilities in the municipality of Lomé.

\section{Material and Methods}

\subsection{Study Design, Location and Population}

This is a cross-sectional, descriptive and analytical study conducted over a period of two months (July - August 2018). It was carried out with mothers of children aged 0 to 23 months who brought their children for consultation at the Growth Monitoring and Promotion Service of a Health Care Centre in the Lome Municipality, Regional Health Department of Togo.

\subsection{Inclusion Criteria}

The minimum sample size of the mother-child pairs in this study was determined from the classic Schwartz formula [9]:

$$
\mathrm{N}=\left(\mathrm{Z}^{2} \times \mathrm{P} \times(1-\mathrm{P})\right) / \mathrm{C}^{2}
$$

Where N: size of the sample; $\mathrm{Z}$ : value corresponding to a given confidence level (1.96 for a 95\% confidence level); P: rate of exclusive breastfeeding in Togo (58\%), [4]; and C: standard error $(5 \%)$.

The cluster effect retained was 1. Using the Schwartz formula, the minimum sample size calculated was 374 mother-child pairs. The sample was increased by $10 \%$ to compensate for non-responses in advance, ie a total of 37 mother-child pairs. Thus, the final size of the sample was 411 mother-child pairs increased to 417 mother-child pairs.

The inclusion criteria for the mothers was to be a mother of a child from 0 to 24 months who came with his child for consultation in the growth monitoring and promotion service of health care centre, thus to be present at the time of the investigation and finally to accept to answer questions.

\subsection{Variables of the Study}

The present study focused on five main types of variables. These are: i) The socio-demographic characteristics of mothers and children: mother's age, educational level, occupation, family situation, age of the child and sex; ii) Obstetrical and neonatal history of mothers: number of mother's pregnancies number of mother's wards, number of prenatal consultations and child's place of delivery; iii) Sources of mother's awareness of infant and young child feeding: awareness raising by health workers during prenatal care, growth monitoring and promotion, and EPI services, and by community health workers on radio, television, markets and neighborhoods; iv) Knowledge of mothers about the benefits of exclusive breastfeeding for the baby and the mother as well as the age of ablation; v) The mothers' level of knowledge about the benefits of exclusive breastfeeding for the baby and the mother.

A scoring system was used to assess women's level of information. In this system, one point was assigned to each correct answer and zero point for each inappropriate answer. The overall score of the level of knowledge is obtained by operating the ratio of the sum of the points allocated to each answer on the total sum of possible points allocated to correct answers. Mothers with a score of zero have no knowledge, those with an overall score below 1 were considered to have a low level of knowledge and those with an overall score equal and above 1 were considered to have a good level of knowledge.

\subsection{Ethical and Administrative Considerations}

Before data collection, the health authorities of the Lome Municipality Regional Health Department were made aware of the study, to which there was no objection. Approval reference was as follows: 0336/2018/MSPS/SG/DRS-LC. In addition, with respect to ethics, the personal consent and favorable opinion of the subjects submitted to the study were obligatory. The technique used for their voluntary membership was to explain the purpose, importance and scope of the study. The subjects were also reassured of anonymity and the confidentiality of the information to be collected.

\subsection{Data Entry and Processing}

The collected data were analyzed with Microsoft Excel (version 2016) and SPSS version 21 software. Associations between the qualitative variables were analyzed using the Chi-square test. Significant level of difference was considered for $P \leq 0.05$.

\section{Results}

\subsection{Socio-demographic Characteristics of Mothers and Their Children}

Mothers ranged from 17 to 47 years old, with an average of $28.4 \pm 0.3$ years. The majority $(86.8 \%)$ of mothers was young (Table 1). In addition, $89.7 \%$ of mothers attended school and 51.3\% attended secondary school. Most were either employed in trade $(34.5 \%)$ or in crafts $(31.9 \%)$, (Table 1).

Table 1. Sociodemographic characteristics of mothers.

\begin{tabular}{lll}
\hline Mother characteristics & Effective & Percentage \\
\hline $\begin{array}{l}\text { Age in years } \\
<18\end{array}$ & 5 & 1.2 \\
\hline
\end{tabular}




\begin{tabular}{|c|c|c|}
\hline Mother characteristics & Effective & Percentage \\
\hline $18-35$ & 362 & 86.8 \\
\hline $36-40$ & 40 & 9.6 \\
\hline$>40$ & 10 & 2.4 \\
\hline \multicolumn{3}{|l|}{ Education level } \\
\hline Illiterate & 43 & 10.3 \\
\hline literate & 18 & 4.3 \\
\hline Primary & 84 & 20.1 \\
\hline Secondary & 214 & 51.3 \\
\hline Higher secondary & 58 & 14.0 \\
\hline \multicolumn{3}{|l|}{ Occupation } \\
\hline None & 86 & 20.6 \\
\hline Farmer & 3 & 0.7 \\
\hline Breeder & 1 & 0.2 \\
\hline Craftswoman & 133 & 31.9 \\
\hline Trader & 144 & 34.5 \\
\hline Public / private employee & 38 & 9.1 \\
\hline Student & 12 & 3.0 \\
\hline \multicolumn{3}{|l|}{ Rank of pregnancy } \\
\hline $1^{\mathrm{st}}$ & 152 & 36.4 \\
\hline $2^{\text {nd }}$ & 131 & 31.4 \\
\hline $3^{\text {rd }}$ & 70 & 16.8 \\
\hline $4^{\text {th }}$ & 44 & 10.6 \\
\hline $5^{\text {th }}, 6^{\text {th }}, 8^{\text {th }}$ & 20 & 4.8 \\
\hline \multicolumn{3}{|l|}{ Prenatal care number } \\
\hline None & 3 & 0.7 \\
\hline$\geq 1$ prenatal care & 414 & 99.3 \\
\hline \multicolumn{3}{|l|}{ Place of delivery } \\
\hline Maternity & 415 & 95.5 \\
\hline Home & 2 & 0.5 \\
\hline \multicolumn{3}{|l|}{ Parity } \\
\hline 1 child & 169 & 40.5 \\
\hline 2 children & 124 & 29.7 \\
\hline 3 children & 72 & 17.3 \\
\hline 4 children & 31 & 7.4 \\
\hline 5 children & 16 & 3.8 \\
\hline 6 children & 5 & 1.2 \\
\hline \multicolumn{3}{|l|}{ Source of awareness on the IYCF } \\
\hline Prenatal care service & 244 & 58.5 \\
\hline Growth monitoring and promotion service & 224 & 53.7 \\
\hline $\begin{array}{l}\text { Expanded programme for immunization } \\
\text { service }\end{array}$ & 261 & 62.6 \\
\hline Community Health worker & 97 & 23.3 \\
\hline Radio & 199 & 47.7 \\
\hline Television & 175 & 42 \\
\hline Market & 50 & 12 \\
\hline Neighborhoods & 59 & 14.1 \\
\hline
\end{tabular}

Mothers have an average of two pregnancies and two children. The proportions of primigravida (36.5\%) and primiparous mothers $(40.5 \%)$ are the highest (Table 1$)$. Almost all mothers had at least one prenatal care (99.2\%) and gave birth in a maternity facility $(95.5 \%)$ (Table 1$)$.

\subsection{Sources of Awareness of Mothers on IYCF}

More than half of the mothers benefited from IYCF counseling in the services of antenatal care $(58.5 \%)$, growth monitoring and promotion (53.7\%) and EPI (62.6\%); while less than half of mothers were informed through radio $(47.7 \%)$ and television (42\%). The least popular sources of awareness were community health workers (23.3\%), neighborhoods (14.1\%) and markets (12\%) (Table 1).

\subsection{Knowledge and Attitudes of Mother Regarding Exclusive Breastfeeding}

The results obtained on mother's opinions concerning the practice of exclusive breastfeeding (EBF) revealed that 342 $(82 \%)$ affirmed that it is possible to perform it against 75 (18\%) affirming the opposite (Table 2). The reasons given by the latter were; the baby's thirst $(68 \%)$, insufficient breast milk is to cover the baby's needs (46.7\%) essential herbal teas, decoctions and infusions for the baby (2.7\%), (Table 2). Mothers who believe that the practice of EBF is possible, have shown its benefits. More than half believed that EBF improves growth and nutritional status $(61.4 \%)$ and reduces diseases such as diarrhea and respiratory infections (55\%). On the other hand, the minority affirmed that EBF can reduce infant mortality (2.6\%), decrease the risk of chronic diseases (3.5\%) and improve psycho-motor, intellectual and emotional development of the child (35.7\%), (Table 2). Regarding the benefits of EBF for the mother, few mothers reported that the practice of EBF reduces the risk of breast and ovarian cancer $(5 \%)$, and prevents the purchase of breast milk substitute $(8.2 \%)$. Others also reported that it promotes an emotional bond between mother and baby $(10.2 \%)$, reduces mother's workload (14\%), reduces child health care expenditure (14.3\%), prevents pregnancy during the earlymonths (14.3\%) and reduces crying of babies (25.7\%), (Table 2).

\subsection{Obstetrical and Neonatal History of Mothers}

Table 2. Knowledge and attitudes of mothers regarding exclusive breastfeeding.

\begin{tabular}{lll}
\hline Knowledge and attitudes of mothers & Effective & Percentage \\
\hline Exclusive breastfeeding feasible $(\mathrm{n}=417)$ & & 18 \\
No & 75 & 417 \\
yes & 342 & 68 \\
Reason for the impossibility of exclusive breastfeeding $(\mathrm{n}=75)$ & 51 & 46.7 \\
Thirst of baby & 35 & 2.7 \\
Insufficient breast milk & 2 & 2.6 \\
Herbal teas, decoctions and infusions are essential for the baby & 9 & \\
Exclusive breastfeeding benefit for the baby $(\mathrm{n}=342)$ & 9 & \\
Decrease infant mortality & & \\
\hline
\end{tabular}




\begin{tabular}{lll}
\hline Knowledge and attitudes of mothers & Effective & Percentage \\
\hline Improves growth and nutritional status & 210 & 61.4 \\
Decreases diseases (diarrhea, etc.) & 188 & 55.0 \\
Improve motor, intellectual and emotional development of the child & 122 & 35.7 \\
Decreases the risk of chronic diseases & 12 & 3.5 \\
Benefits of BFE for mother (n = 342) & 88 & 25.7 \\
Decreases the crying of the baby & 49 & 14.3 \\
Reduces child health care expenditure & 28 & 8.2 \\
Prevents the purchase of breast milk substitute & 35 & 10.2 \\
Promotes the emotional bond between the mother and the baby & 48 & 14 \\
Reduces the mother's workload & 49 & 14.3 \\
Prevents pregnancy the first months & 17 & 5 \\
Reduces the risk of breast and ovarian cancer & \\
\hline
\end{tabular}

\subsection{Level of Mother's Knowledge Regarding the Benefits of EBF and Associated Factors}

The evaluation of the mother's level of knowledge about the benefits of exclusive breastfeeding (EBF) revealed that $43.9 \%$ and $19.7 \%$ of mothers had a good knowledge of the benefits of EBF for the baby and for the mother, respectively
(Table 3 and Table 4). Levels of mother's knowledge regarding the benefits of EBF for mother and baby are significantly associated with sensitization by health workers $(P=0.0001)$, (Table 3 and Table 4). However, only the level of mother's knowledge about the benefits of EBF for the baby is significantly associated with mass media sensitizations $(P=0.036)$, (Table 3$)$.

Table 3. Levels of mother's knowledge regarding the benefits of BFE for the baby and related factors.

\begin{tabular}{|c|c|c|c|c|}
\hline \multirow{2}{*}{ Associated factors } & \multicolumn{4}{|c|}{ Level of mother's knowledge about the benefits of EBF for the baby } \\
\hline & No knowledge n (\%) & Low knowledge n (\%) & Good knowledge n (\%) & P-value \\
\hline Total & $125(30)$ & $109(26.1)$ & $183(43.9)$ & \\
\hline \multicolumn{5}{|l|}{ Maternal age (years) } \\
\hline$<18$ & $0(0.0)$ & $3(2.8)$ & $2(1.1)$ & \multirow{4}{*}{0.415} \\
\hline $18-35$ & $113(90.4)$ & $91(83.5)$ & $158(86.3)$ & \\
\hline $36-40$ & $10(8.0)$ & $13(11.9)$ & $17(9.3)$ & \\
\hline$>40$ & $2(1.6)$ & $2(1.8)$ & $6(3.3)$ & \\
\hline \multicolumn{5}{|l|}{ Education level } \\
\hline Illiterate & $13(10.4)$ & $9(8.3)$ & $21(11.5)$ & \multirow{5}{*}{0.980} \\
\hline Literate & $7(5.6)$ & $5(4.6)$ & $6(3.3)$ & \\
\hline Primary & $24(19.2)$ & $23(21.1)$ & $37(20.2)$ & \\
\hline Secondary & $65(52.0)$ & $57(52.3)$ & $92(50.3)$ & \\
\hline Superior & $16(12.8)$ & $15(13.8)$ & $27(14.8)$ & \\
\hline \multicolumn{5}{|l|}{ Occupation } \\
\hline None & $34(27.2)$ & $24(22.0)$ & $28(15.3)$ & \multirow{7}{*}{0.315} \\
\hline Farmer & $1(0.8)$ & $1(0.9)$ & $1(0.5)$ & \\
\hline Breeder & $1(0.8)$ & $0(0.0)$ & $0(0.0)$ & \\
\hline Craftswoman & $43(34.4)$ & $33(30.3)$ & $57(31.1)$ & \\
\hline Trader & $36(28.8)$ & $35(32.1)$ & $73(39.9)$ & \\
\hline Public / private employee & $7(5.6)$ & $12(11.0)$ & $19(10.4)$ & \\
\hline Student & $3(2.4)$ & $4(3.7)$ & $5(2.7)$ & \\
\hline \multicolumn{5}{|c|}{ Awareness raising with health workers } \\
\hline No source & $42(33.6)$ & $24(22.0)$ & $24(13.1)$ & \multirow{2}{*}{0.0001} \\
\hline At least one source & $83(66.4)$ & $85(78.0)$ & $159(86.9)$ & \\
\hline \multicolumn{5}{|c|}{ Awareness raising with the mass media } \\
\hline No source & $55(44.0)$ & $45(41.3)$ & $56(30.6)$ & \multirow{2}{*}{0.036} \\
\hline At least one source & $70(56.0)$ & $64(58.7)$ & $127(69.4)$ & \\
\hline \multicolumn{5}{|l|}{ Place of delivery } \\
\hline Maternity & $123(98.4)$ & $109(100.0)$ & $183(100.0)$ & \multirow{2}{*}{0.096} \\
\hline Home & $2(1.6)$ & $0(0.0)$ & $0(0.0)$ & \\
\hline \multicolumn{5}{|c|}{ Participation at prenatal care } \\
\hline Yes & $123(98.4)$ & $108(99.1)$ & $183(100.0)$ & \multirow{2}{*}{0.254} \\
\hline No & $2(1.6)$ & $1(0.9)$ & $0(0.0)$ & \\
\hline \multicolumn{5}{|l|}{ Gravida } \\
\hline Primigravida & $50(40.0)$ & $42(38.5)$ & $60(32.8)$ & \multirow{3}{*}{0.339} \\
\hline Paucigravida & $61(48.8)$ & $52(47.7)$ & $88(48.1)$ & \\
\hline Multigravida & $14(11.2)$ & $15(13.8)$ & $35(19.1)$ & \\
\hline \multicolumn{5}{|l|}{ Parity } \\
\hline Primiparous & $53(42.4)$ & $44(40.4)$ & $72(39.3)$ & \multirow{3}{*}{0.797} \\
\hline Pauciparous & $59(47.2)$ & $53(48.6)$ & $84(45.9)$ & \\
\hline Multiparous & $13(10.4)$ & $12(11.0)$ & $27(14.8)$ & \\
\hline
\end{tabular}


Table 4. Levels of mother's knowledge regarding the benefits of BFE for the mother and related factors.

\begin{tabular}{|c|c|c|c|c|}
\hline \multirow{2}{*}{ Associated factors } & \multicolumn{4}{|c|}{ Level of mother's knowledge about the benefits of EBF for the baby } \\
\hline & No knowledge n (\%) & Low knowledge n (\%) & Good knowledge n (\%) & p-value \\
\hline Total & $235(56.3)$ & $100(24)$ & $82(19.7)$ & \\
\hline \multicolumn{5}{|l|}{ Maternal age (years) } \\
\hline$<18$ & $1(0.4)$ & $2(2.0)$ & $2(2.4)$ & \multirow{4}{*}{0.223} \\
\hline $18-35$ & $206(87.7)$ & $83(83.0)$ & $73(89.0)$ & \\
\hline $36-40$ & $25(10.6)$ & $11(11.0)$ & $4(4.9)$ & \\
\hline$>40$ & $3(1.3)$ & $4(4.0)$ & $3(3.7)$ & \\
\hline \multicolumn{5}{|l|}{ Education level } \\
\hline Illiterate & $24(10.2)$ & $11(11.0)$ & $8(9.8)$ & \multirow{5}{*}{0.381} \\
\hline literate & $12(5.1)$ & $3(3.0)$ & $3(3.7)$ & \\
\hline Primary & $48(20.4)$ & $19(19.0)$ & $17(20.7)$ & \\
\hline Secondary & $126(53.6)$ & $45(45.0)$ & $43(52.4)$ & \\
\hline Superior & $25(10.6)$ & $22(22.0)$ & $11(13.4)$ & \\
\hline \multicolumn{5}{|l|}{ Occupation } \\
\hline None & $53(22.6)$ & $19(19.0)$ & $14(17.1)$ & \multirow{7}{*}{0.627} \\
\hline Farmer & $1(0.4)$ & $2(2.0)$ & $0(0.0)$ & \\
\hline Breeder & $1(0.4)$ & $0(0.0)$ & $0(0.0)$ & \\
\hline Craftswoman & $77(32.8)$ & $25(25.0)$ & $31(37.8)$ & \\
\hline Trader & $77(32.8)$ & $38(38.0)$ & $29(35.4)$ & \\
\hline Public / private employee & $20(8.5)$ & $12(12.0)$ & $6(7.3)$ & \\
\hline Student & $6(2.6)$ & $4(4.0)$ & $2(2.4)$ & \\
\hline \multicolumn{5}{|c|}{ Awareness raising with health workers } \\
\hline No source & $67(28.5)$ & $17(17.0)$ & $6(7.3)$ & \multirow{2}{*}{0.0001} \\
\hline At least one source & $168(71.5)$ & $83(83.0)$ & $76(92.7)$ & \\
\hline \multicolumn{5}{|c|}{ Awareness raising at the mass media level } \\
\hline No source & $97(41.3)$ & $34(34.0)$ & $25(30.5)$ & \multirow{2}{*}{0.159} \\
\hline At least one source & $138(58.7)$ & $66(66.0)$ & $57(69.5)$ & \\
\hline \multicolumn{5}{|l|}{ Place of delivery } \\
\hline Maternity & $234(99.6)$ & $99(99.0)$ & $82(100)$ & \multirow{2}{*}{0.614} \\
\hline Home & $1(0.4)$ & $1(1.0)$ & $0(0)$ & \\
\hline \multicolumn{5}{|l|}{ Participation at prenatal care } \\
\hline Yes & $233(99.1)$ & $99(99.0)$ & $82(100.0)$ & \multirow{2}{*}{0.683} \\
\hline No & $2(0.9)$ & $1(1.0)$ & $0(0)$ & \\
\hline \multicolumn{5}{|l|}{ Gravida } \\
\hline Primigravida & $86(36.6)$ & $37(37.0)$ & $29(35.4)$ & \multirow{3}{*}{0.997} \\
\hline Paucigravida & $114(48.5)$ & $47(47.0)$ & $40(48.8)$ & \\
\hline Multigravida & $35(14.9)$ & $16(16.0)$ & $13(15.9)$ & \\
\hline \multicolumn{5}{|l|}{ Parity } \\
\hline Primiparous & $96(40.9)$ & $42(42.0)$ & $31(37.8)$ & \multirow{3}{*}{0.979} \\
\hline Pauciparous & $109(46.4)$ & $46(46.0)$ & $41(50.0)$ & \\
\hline Multiparous & $30(12.8)$ & $12(12.0)$ & $10(12.2)$ & \\
\hline
\end{tabular}

\section{Discussion}

The practice of EBF until 6 months of age has beneficial effects on the child's good growth and the mother must have satisfactory knowledge of its benefits [10]. The results of the study revealed that the average age of mothers was $28.4 \pm 0.3$ years which is higher than those found by Djadou (27.5 years) in Tchaoudjo district of Togo and by Siri (26.7 years \pm 6.4) in rural areas in the Ouargaye district of Burkina Faso $[11,12]$. It also revealed that data on enrolment rates of $89.7 \%$ and educational attainment of $51.3 \%$ of mothers are slightly higher than those reported by the Demographic and Health Survey (DHS) of Togo in the greater Lomé agglomeration (Municipality of Lomé and the urban areas of the Golfe prefecture) [4]. In fact, previous DHS (84.1\%) found of those enrolled with a high proportion of mothers with secondary level of $43.1 \%$ [5].

The proportion of mothers who gave birth in health facility $(95.5 \%)$ is higher than that reported by Djadou et al., which was $85.3 \%$ in the health district of Tchaoudjo in Togo [11]. The number of sensitization activities made in the community over time and the urban location of the health district could explain this difference. In terms of sources of information on infant and young child nutrition (IYCN), mothers are more aware of maternal and child health services, radio and television. This observation is in line with that of mothers of children aged 6 to 24 months surveyed on IYCF by Brou-Tanoh et al. in Cote d'Ivoire [13]. Mother's declarations show that health workers and the media have an important role in popularizing IYCF practices among the population. To achieve optimal growth, development and health, infants must be breastfed exclusively for the first six months of life $[1,2,14]$. Notwithstanding this recommendation, mothers have different attitudes for various reasons. The proportion of mothers $(18 \%)$ who believe that EBF cannot be practiced is lower than $45.6 \%$ observed by UNICEF in the population of Burkina Faso [15]. The reasons for the baby's thirst and breast milk insufficiency affirmed by the mothers surveyed are also evoked by a smaller proportion 
of mothers in the department of Gaya in Niger during the study on the knowledge, attitudes, perception and practice of the populations about maternal and child health [16].

These reasons are also found in Burkina Faso population by UNICEF [15]. Indeed, the women surveyed by UNICEF believed that breast milk is not a source of water for the baby and that it is necessary to purify and whet the infant's appetite by herbal concoctions, which are also used for shower. Among the mothers surveyed who believe that EBF is possible and cited its benefits, the proportion who affirmed that EBF improves the motor, intellectual and emotional development of the child, decreases diseases, promotes the emotional bond between mother and baby, prevents pregnancy during the first early months are lower than those found by Siri in Burkina Faso which were respectively $45.5 \%, 89.5 \%, 97.2 \%$ and $31.8 \%$ [12]. However, the proportion of mothers who agreed that EBF improves growth and nutritional status is higher than that reported by Siri which was $58.4 \%$ [12]. In addition, the proportion of mothers who reported that EBF reduces the risk of breast and ovarian cancer is lower than $17.6 \%$ reported by Bashir et al. in India [17].

On the other hand, the proportion of mothers who declared that EBF saves income and previously used to purchase breast milk substitutes is higher than that reported in Burkina Faso by UNICEF which was 3\% [15]. Mothers who have a good knowledge of the benefits of EBF for the baby (43.9\%) are significantly higher than mothers who have a good knowledge of the benefits of EBF for the mother (19.7\%). However, the levels of knowledge of mothers about the benefits of EBF for mother and baby are significantly associated with sensitization by health workers. Other data showed [18, 19], a relationship between knowledge of the benefits of breastfeeding by mothers and awareness raising among health workers during the prenatal period.

These results show that health workers and the mass media need to strengthen their information and awareness-raising activities on the benefits of exclusive breastfeeding, especially for mothers.

\section{Conclusion}

The practice of EBF is feasible according to the majority of mothers in the municipality of Lome. However, less than half of these mothers who affirmed that the practice of EBF is possible had a good knowledge of its benefits. The levels of knowledge of mothers about the benefits of EBF for the mother and baby depended on the sensitization made by health workers. Moreover, the level of knowledge of mothers about the benefits of EBF for the baby also depended on the awareness received through the mass media.

\section{Acknowledgements}

All workers at Lome health District and at the Nutrition Division. All women who accepted to be part of this study.

\section{References}

[1] Fewtrell M. S. The evidence for public health recommendations on infant feeding. Early Human Development. 2011; 87: 715-721.

[2] OMS, (2001). 54 Assemblée mondiale de la Santé. La nutrition chez le nourrisson et le jeune enfant, 2001. (http://www.who.int/gb/ebwha/pdf_files/WHA54/fa54r2.pdf).

[3] Infant and Young Child Nutrition (IYCN), (2008). Normes nationales relatives à l'alimentation du nourrisson, du jeune enfant sains et ceux nés de mères séropositives, p. 94.

[4] Ministère de la Planification, du Développement et de l'Aménagement du Territoire (MPDAT), Ministère de la Santé (MS) et ICF International, Enquête Démographique et de Santé au Togo (EDST) 2013-2014 (2015). Rockville, Maryland, USA: MPDAT, MS et ICF International.

[5] Ministère de la Santé (MS), Ministère de l'agriculture de l'élevage et de la pêche (MAEP), Ministère de la planification $\mathrm{du}$ développement et de l'aménagement du territoire (MPDAT), Vulnérabilité Alimentaire et Nutritionnelle en Milieu Urbain à Lomé. (2012).

[6] Tunde A. Alabi, Samuel O. Adejoh, Sonnen Atinge, et al. Social and bio-medical predictors of exclusive breastfeeding among nursing mothers in Lagos and Taraba States, Nigeria. Journal of Pediatric Nursing 2019. In press, https://doi.org/10.1016/j.pedn.2019.12.002

[7] Desclaux A, Taverne B. Allaitement et VIH en Afrique de l'Ouest: Del'anthropologie à la santé publique. Face à face Regards sur la santé 2001, 3.

[8] U.S. Department of Health and Human Services (DHHS), 2011. The Surgeon General's Call to Action to Support Breastfeeding.

[9] Schwartz D. Statistical methods for physicians and biologists. Paris, France: Madrigall Group, Ed. Flammarion Medecins Sciences, 1969.

[10] Black R E, Allen L H, Bhutta Z A, et al. Maternal and child undernutrition: global and regional exposures and health consequences. The lancet 2008, 371 (9608), pp. 243-260.

[11] Djadou K E, Agbeko F, Guédéhoussou T, et al. Evaluation de l'allaitement maternel exclusif chez les enfants de 0 à six mois dans le district de Tchaoudjo (Togo). J Afr Pediatr Genet Med 2018, 4, pp. 30-36.

[12] Siri B A A, Bengaly M, Garanet F, et al.. Knowledge, opinions and attitudes of mothers about breastfeeding and child feeding in rural areas of Burkina Faso: a study in Ouargaye's district health facilities. Journal of Family Medicine and Health Care 2018; 4: 3, pp. 13-19.

[13] Brou-Tanoh A M, Etiegne M S, Bosso P, Kourouma R, et al. Les pratiques d'alimentation du nourrisson et du jeune enfant en côte d'ivoire: cas de l'alimentation de complément des enfants de 6-24 mois. Cahier de Santé Publique 2010, 9 (2), pp. 7-20.

[14] OMS/UNICEF, (2003). Stratégie mondiale pour l'alimentation du nourrisson et du jeune enfant. Organisation Mondiale de la Santé, Genève. 
[15] UNICEF, (2012). Etude sur les connaissances, attitudes et pratiques (CAP) concernant les six pratiques familiales essentielles (PFE) au Burkina Faso.

[16] Bara I, Souley A, (2012). Analyse des connaissances, attitudes, perceptions et pratiques des populations en matière de santé de la mère et de l'enfant dans le département de Gaya.

[17] Bashir A, Mansoo S, Naikoo M Y. Knowledge, attitude, and practices of postnatal mothers regarding breastfeeding: A cross-sectional study. Int J Med Sci Public Health 2018, 7 (9), pp. $725-731$.

[18] Chaturvedi P, Banait N. Knowledge and attitude regarding breast-feeding, in mothers attending antenatal clinics. Indian J. Pediatr 2000, 67 (4), pp. 259-262.

[19] Kornides M, Kitsantas P. Evaluation of breastfeeding promotion, support, and knowledge of benefits on breastfeeding outcomes. J. Child Health Care 2013, 17 (3), pp. 264-273. 